\title{
Developing Better Measures of Neighbourhood Characteristics and Change for Use in Studies of Residential Mobility: A Case Study of Britain in the Early 2000s
}

\author{
Ludovica Gambaro $^{1}$ - Heather Joshi ${ }^{1}$. \\ Ruth Lupton $^{2}$ - Alex Fenton ${ }^{3}$ - Mary Clare Lennon ${ }^{4}$
}

Received: 4 December 2014 / Accepted: 24 July 2015 /

Published online: 18 August 2015

(C) The Author(s) 2015. This article is published with open access at Springerlink.com

\begin{abstract}
This paper addresses the problem of measuring neighbourhood characteristics and change when working with individual level datasets to understand the effects of residential mobility. Currently available measures in Britain are in various respects unsuitable for this purpose. The paper explores a new indicator of small area poverty: the Unadjusted Means-tested Benefits Rate (UMBR), which divides claimants of means-tested benefits in a small area by the number of households. We describe changes in area poverty between 2001 and 2006, using UMBR. As often assumed, these are generally negligible, but small areas in "disadvantaged urban" and "multicultural city life" communities did change considerably in this period. We also link UMBR to the first three waves of the UK Millennium Cohort Study, a survey of families with children born at the beginning of the 2000s. We examine opinions about
\end{abstract}

Ludovica Gambaro

1.gambaro@ioe.ac.uk

Heather Joshi

heather.joshi@ioe.ac.uk

Ruth Lupton

ruth.lupton@manchester.ac.uk

Alex Fenton

alex.fenton@pressure.to

Mary Clare Lennon

MLennon@gc.cuny.edu

1 UCL Institute of Education, University College London, Gower Street, London WC1E 6BT, UK

2 School of Environment, Education and Development, University of Manchester, Manchester M13 9PL, UK

3 Leibniz Universität Hannover, Postfach 6009, 30060 Hannover, Germany

4 Graduate Centre, City University, 365 Fifth Avenue, New York, NY 10016, USA 
neighbourhood and find that parents living in areas of higher poverty did tend to express more negative views than those living elsewhere. Living in high poverty areas was also associated with moving home, and those families who retrospectively gave neighbourhood considerations as reasons for moving did move into areas with markedly lower poverty rates. Finally, we compare families' moving trajectories to trends in poverty within areas. We are able to show that a large proportion of families who moved to poorer neighbourhoods were at double disadvantage, as they often moved to areas with increasing poverty rates. We conclude that UMBR can be used to enhance understanding of changing neighbourhood contexts in cohort studies, at least for this period, although it still suffers from the same conceptual and technical difficulties as other available alternatives in terms of its ability to capture aspects of neighbourhood quality.

Keywords Poverty measurement $\cdot$ Neighbourhood characteristics $\cdot$ Residential mobility Cohort studies · Children

\section{Introduction}

This paper is concerned with the measurement of change over time in the characteristics of neighbourhoods in Britain. To be clear, since readers will approach this paper from very different kinds of interests in neighbourhood change, our purpose is not primarily to contribute the evidence on the changing characteristics of different kinds of neighbourhoods through processes of economic decline and growth, migration or gentrification or under the influence of different policy regimes (Power and Mumford 1999; Lupton 2003; Tunstall and Coulter 2006; Butler 2007; Foden et al. 2014; Lupton and Fitzgerald 2015). We do shed some light on these issues. However, our main purpose is to see whether there are measures of neighbourhood characteristics and change suitable for matching to individual-level datasets. Such matching will tell us something about the context in which individuals are living, how this changes over time and what happens when people move. We examine one such measure and put it to the test.

The development of better neighbourhood measures has two purposes. One is to understand the scale of 'neighbourhood effects' on individual outcomes, such as health or education. A typical approach is to compare the outcomes of people living in neighbourhoods with different characteristics, measured at a particular point in time, and controlling for other individual and household characteristics (van Ham et al. 2012). There are measures in Britain that are broadly fit for these purposes, for example Census-based measures and the Indices of Multiple Deprivation or IMDs, although these have some limitations, as discussed later. However, an additional complexity is introduced when we try to understand neighbourhood effects over time: so called 'dosage' effects. This requires knowledge of how neighbourhoods have changed in the period under examination - it cannot be assumed that all neighbourhoods will have retained the characteristics identified at the first time point.

A second purpose is to better understand the effects of residential mobility. Some studies of mobility, famously the US Moving to Opportunity programme, are specifically concerned with what happens when people move to different 
neighbourhoods (Briggs et al. 2010). Neighbourhood characteristics are the core of the enquiry. Comparison between the neighbourhoods families have left and those they have moved to may appear straightforward, but requires a measure able to capture neighbourhood characteristics at two points in time. There are also other studies which are concerned with exploring the effects of moving per se. Factors to be considered in determining whether moving matters and in what kinds of circumstances will include the characteristics of the neighbourhoods of origin and destination but also changes in housing size and quality, employment and family structure (Verropoulou et al. 2002; Jellyman and Spencer 2008; Rabe and Taylor 2010; Tunstall et al. 2010). In both kinds of studies, it is necessary to identify the characteristics of the neighbourhoods moved from and to, but also any neighbourhood change over time. Without this, we cannot accurately compare the experiences of the movers and stayers. Stayers may also have experienced change from a 'good' neighbourhood to a 'bad' one, for example, if the characteristics of the neighbourhood have changed around them. This latter type of change is commonly overlooked in residential mobility studies, which might be something of a surprise to people studying the dynamics of area change per se.

The first section of the paper reviews the measures most commonly used to describe neighbourhoods in the UK-the Indices of Multiple Deprivation (IMDs). As we explain, we find these measures ill-suited to capture the absolute change achieved by relocation and unable to tell us anything about over time change within neighbourhoods. As an alternative we present a new proxy measure for neighbourhood poverty known as UMBR (the Unadjusted Means-tested Benefit Rate). In the following section, we examine the distribution of UMBR and compare it to the IMDs and other measures, to clarify what it does and does not measure, and to test its robustness and reliability. We then move to describe neighbourhood change in Britain between 2001 and 2006, as captured by UMBR. A particular contribution of the paper is to compare the account of neighbourhood characteristics and change given by UMBR (an objective measure) with the subjective assessments made by residents of those neighbourhoods. To do this, we link UMBR to a rich longitudinal survey, the Millennium Cohort Study (MCS), which follows a sample of children born in 2000/01 from the UK. In the fourth section, we look at the first three 'sweeps' of this study, covering the period up to 2006, observing not only the parent's subjective assessments of their neighbourhoods at different time points, but their moving trajectories from one neighbourhood to another. The last section concludes.

Thus we are able to describe what UMBR (on its own) tells us about small area change in Great Britain in that period, assess its fit with subjective measures and also examine the relationship between area change and family mobility trajectories. Are young families who move escaping declining neighbourhoods, for example, or moving into worse ones in order to get a foothold in the housing market? By juxtaposing individual families' trajectories - from one neighbourhood to another - to the trajectories of neighbourhood themselves - as captured by UMBR — we are able to further our understanding of mobility choices. We also provide both the first empirical test of UMBR and a demonstration and discussion of how small area administrative data and longitudinal micro-data can be used together in mutually enhancing ways. 


\section{Quantifying Neighbourhood Change in the UK: Challenges and Existing Measures}

Despite burgeoning interest in the last decade in measuring neighbourhood effects on individual outcomes, there remain well documented difficulties in capturing relevant aspects of neighbourhood environments, at relevant spatial scales, through census, administrative or survey data.

A first problem is the identification of neighbourhoods. Administrative or statistical geographies may not reflect subjective neighbourhoods (Massey 1994; Kearns and Parkinson 2001; Robinson 2010). Kwan (2012) defines this as the 'uncertain geographic context problem', arising from 'the spatial uncertainty in the actual areas that exert contextual influences on the individuals being studied and the temporal uncertainty in the timing and duration in which individuals experienced these contextual influences" ( $p$ 959). What constitutes the relevant neighbourhood may vary from person to person. Orford and Leigh (2014) found that young and retired people defined larger neighbourhoods than other residents, but also that people living or working close to one another did not necessarily share the same neighbourhood definitions even if they had similar personal characteristics. Even when boundaries are drawn, the relevant characteristics may vary over space within them-the characteristics of the space closest to a point may be quite different from those of the areal unit in which that point lies (Cohn and Jackman 2011). All of these considerations highlight the need to develop more sophisticated measures of neighbourhood characteristics relating to subjective geographies. Examples of such approaches are beginning to emerge in the literature. For example, Vallée et al. (2014) created 'perceived neighbourhood polygons' based on cognitive neighbourhood data collected among 653 residents of the Paris metropolitan area. Inequalities in health resources were found to be wider using these boundaries than using 'constant size' neighbourhoods, suggesting that the typically-used measures obscured important differences in residents' lived experiences.

A second issue is the complexity of neighbourhood characteristics. Galster (2012) for example, suggests that neighbourhoods can influence residents through four broad kinds of mechanisms: social interactive mechanisms (such as social networks or disorder); environmental mechanisms (such as fear of violence or pollution), geographical mechanisms (such as inaccessibility) and institutional mechanisms (such as poor amenities or neighbourhood reputation). Furthermore these characteristics may not be understood or experienced in the same way or to the same extent by all residents. As Clapham (2005) points out, it would be possible to take an entirely social constructionist view on both housing and neighbourhood 'quality', such that there are no universal truths and that people will appreciate different aspects of their home and neighbourhood depending on their housing pathway, attitudes and lifestyle. This would make any objective measure of neighbourhood quality impossible.

Third, there is the issue of capturing neighbourhood change, which requires the same measures to be repeatedly collected, and introduces a fresh set of complexities less commonly visited in the existing literature. These include the question of adaptive preferences and also whether what is relevant is the scale of change relative to a starting point, change relative to other areas, or absolute change, including the issue of whether only changes exceeding a certain magnitude are visible and important to residents. 
In the UK, the most common approach to measuring neighbourhood 'quality' is to use the indices of multiple deprivation developed in the 2000s. In England the Index of Multiple Deprivation (IMD, Office of the Deputy Prime Minister 2004) built on previous indices of 'local conditions' (ILC) and 'local deprivation (ILD) but included a much wider range of data, covering aspects of deprivation related to income, education, health, housing, crime and access to services. Similar, but not identical, indices were also produced by the devolved administrations in Scotland (SIMD), Wales (WIMD) and Northern Ireland (NIMDM), and produced intermittently during the 2000s, at 3 to 5 year intervals (Scottish Executive, Office of the Chief Statistician 2004; National Assembly for Wales, Statistical Directorate 2005; Northern Ireland Statistics and Research Agency 2005).

These indices have some advantages for research purposes. They are produced with more regularity than the decennial Census, so are valuable for inter-censal periods, while Census-based measures (such as the Townsend Index of deprivation) can be used with harmonised components and boundaries over time to analyse longer run change (Norman 2010). The IMDs also go some way to capturing the complexity of neighbourhoods, in that they conceive neighbourhoods as characterised by multiple physical, social and economic dimensions, although economic deprivation-income poverty and unemployment-receives heavy weighting. They do not address the uncertain geographic context problem - 'neighbourhood' is defined in terms of the statistical geographies of the 2001 Census, the Lower Super Output Area (LSOA) in England and Wales and the smaller Datazone in Scotland. ${ }^{1}$ The IMDs are also ill-suited for use in analysis covering the whole UK, since they are not easily combined across the four UK countries, with differences in the data used and deprivation domains included. Payne and Abel (2012) propose a method for deriving harmonised indices, but the difficulty remains that each country's indices relate to different years. ${ }^{2}$

Most problematically for residential mobility studies, the IMDs are not suitable for quantifying improvement or decline made by moving neighbourhood, because of statistical transformations applied during their construction. Nor can they be used to describe change in neighbourhood over time. Their original and chief purpose was to bring out the relative position of neighbourhoods across multiple domains of deprivation at a single point in time. Most individual domain measures have a "natural" interpretation as the proportion of people experiencing the deprived state: on benefit, without work, sick, badly housed, etc. However, to produce overall deprivation scores, exponential transformations are applied to each domain measure before they are summed and weighted (McLennan et al. 2011, p.133). This is intended to ensure that a very high score on one domain is not cancelled out by a low score in another. As a result, the scale and direction of absolute real change in the proportion of people experiencing deprivation cannot be derived from changes over time in the overall score. Also, similar changes in underlying scores can have different effects on a neighbourhood's rank position depending on its starting rank.

In this paper we are interested in measuring change achieved by relocation and change over time within neighbourhoods. We therefore adopt another measure: the

\footnotetext{
${ }^{1}$ LSOAs in England and Wales had a mean population of roughly 1600 in 2010; Datazones in Scotland, 800.

2 In our period of interest, England IMD 2004 and 2007, Scotland 2004 and 2006, WIMD 2005 and 2008, Northern Ireland 2001 (using earlier data) and 2005.
} 
Unadjusted Means-tested Benefit Rate (UMBR) which has been devised explicitly for tracking micro-spatial changes in poverty over time (see Fenton 2013a). ${ }^{3}$ It covers the three nations of Great Britain, for the period 2001-2011, although not, unfortunately, Northern Ireland, where the data was not available at the requisite spatial scale. To our knowledge, UMBR has not yet been used empirically alongside survey data, thus the paper provides the first test of its utility as a measure of neighbourhood change.

\section{UMBR and its Distribution}

The UMBR measure was developed during 2012 at the London School of Economics to support analysis of changes in the spatial distribution of poverty under the Labour government from 1997 to 2010 and under the Coalition government from 2010 onwards. The team sought a small-area measure of poverty which could be produced annually from publicly available data, updated without long time lags in order to assess current policies, and which was a 'real number' rather than a synthetic score.

In contrast to the more complex IMDs, UMBR concentrates on just one variable, the ratio of claimants of means-tested benefits to the number of households in a small area in Great Britain. The numerator is the sum of all claimants of Jobseeker's Allowance (income-based or contribution-based), Income Support, Employment Support Allowance and Pension Credit (Guarantee Element), in each LSOA or Datazone, averaged over the four quarters of each calendar year. These benefits are mutually exclusive, as only one may be claimed at a time, and shared, in that only one claim may exist within a "benefit unit" - a single adult or couple and any dependent children living with them. UMBR thus draws on source data also used in the Income Domain of IMD, which is available only for those years covered by the overall IMDs. But, unlike the income domain subscales, UMBR does not use data about means-tested benefits and transfers for people in work, such as Housing Benefit and Tax Credits, which are not available at the required scale across the period. The denominator of this ratio is the estimated number of households in the area, which is a proxy for the number of benefit units. As explained by Fenton (2013a: 61-62), the use of households rather than individuals is more appropriate when comparing poverty rates across small areas, as they better account for differences in family size. Small-area household estimates are not published as official statistics, so were created for this purpose by applying a demographic headship model to published population estimates (see Fenton 2013b). The next section explores how UMBR may change due to changes in either its numerator or denominator.

Conceptually, UMBR is a proxy measure of neighbourhood-level poverty rates. It is not, like IMD, a measure of multiple deprivation, nor does it directly capture any of the social-interactive, environmental, geographical or institutional factors that may produce neighbourhood effects. It is also not a perfect proxy for poverty as conceived and measured in specialised surveys. It includes neither income-poor households in work, nor out-of-work poor households

\footnotetext{
${ }^{3}$ The dataset is publicly available at http://eprints.1se.ac.uk/46449/ and full details of the dataset are given in Fenton (2013b). The dataset has been updated in 2015 to make use of the 2011 Census and new administrative data; this later version is available at http://eprints.lse.ac.uk/61169/.
} 
who are ineligible for benefits, nor those who are eligible but do not claim. An important assumption is that the spatial distribution of income poverty overall is strongly correlated with that of out-of-work means-tested benefit claims (see Fenton 2013a for further details and tests).

Like the IMDs, UMBR is available for pre-defined geographic units: Lower Super Output Areas (LSOAs) in England and Wales and Datazones (DZs) in Scotland. Although the boundaries are drawn in order to maximise social homogeneity within areas and to take into account geographical barriers and edges of settlements, the question remains as to what extent such geographical units correspond to what residents refer to as "neighbourhood" and the comparison with MCS data later in the paper will shed some light on this.

Here we look at the distribution of UMBR between 2001 and 2006. We restrict our attention to this period for two reasons. First, the period corresponds to the pre-school years in the MCS, in which we examine residential mobility in the second half of the paper. Second, we wanted to exclude the years after the 2008 economic crisis, as that event heralds an unprecedented change that would have clouded any previous trend.

The 40,883 small areas in Great Britain varied enormously in the rate of claiming out-of-work means-tested benefits in the 5 years up to 2006. The mean level of UMBR was around $20 \%$, but skewed towards lower levels. Values between 5 and $10 \%$ were common, accounting for approximately one fifth of all areas. Only $5 \%$ of all areas had an UMBR above $50 \%$. Low levels of UMBR were particularly common in England. The regional pattern within England showed LSOAs in the South and in the East of England (excluding London) as having markedly lower average UMBR, at around $14 \%$, also reflecting the North-south divide. These statistics should not be confused with commonly reported ratios of benefit claimants calculated over the working-age population. By using households at the denominator, UMBR tends to report higher percentages.

Although UMBR does not solve all of the challenges in neighbourhood measurement, such as the complexity of neighbourhood characteristics, their subjective importance and the question of individualised geographies, its advantage for purposes like ours is that it is a very straightforward measure, using natural units. UMBR is available and comparable annually across the whole of Great Britain. It therefore overcomes the principal limitations of the IMDs for use in neighbourhood change analysis, of being country-specific and intermittently issued during the 2000s.

Notwithstanding these differences, UMBR and the IMDs are closely correlated empirically. Comparing UMBR to the overall IMDs revealed a correlation of 0.93 in both England and Wales, and 0.95 in Scotland. This should perhaps be unsurprising given that, although broader in their concept of area deprivation, the IMDs are heavily weighted on the income and employment domains, which are central to UMBR. UMBR correlated particularly highly to the income domain in the IMDs (0.97), suggesting that UMBR is not missing places with high proportions of the working poor, despite not including such families in its numerator. The advantage of UMBR over the income domain score is that by being available annually it allows a more flexible choice of period. 


\section{What Does UMBR Tell Us About Area Change?}

UMBR, therefore, allows us to document neighbourhood stability and change in ways that the IMDs do not. In this section, we look at which areas changed most in 20012006, considering both the numerator and denominator of UMBR.

In aggregate terms, the level of poverty as measured by UMBR remained almost identical from 2001 to 2006. Accordingly, the average change experienced by most individual small areas was rather small: less than half percentage point on average (Table 1). This masks larger changes among a small proportion of areas, as shown in Fig. 1. Comparing 2001 and 2006, UMBR changed by at least 5 percentage points in $9 \%$ of all small areas. Changes of this magnitude appeared to be more common in poorest areas, while initially lower levels of poverty were associated with very little change (Table 2).

Given that UMBR is a ratio, it can change either because the number of benefit recipients changes or the number of households does. Thus, to elaborate the picture further, we constructed a 6 -fold classification of areas, which combines two variables: the direction of change (improving, declining or unchanging) and whether that change is in the number of benefit recipients or of households. The latter distinction is important, as these situations may, in reality, mean very different things. For example compare the differences between a reduction in poverty of the original inhabitants and the arrival of non-claiming households while the poverty of the original households persists (Table 3).

We took a pragmatic approach to defining an area as improving or declining based on the distribution of change illustrated in Table 1, taking the simple change and standardising it to have mean 0 and standard deviation 1 . We classified as "improving" areas whose UMBR rate fell by more than half a standard deviation, corresponding, on average, to a reduction of almost 4 percentage points (3.8). Symmetrically, "declining" were areas whose UMBR rate increased more 3.8 percentage points. Areas whose UMBR did not change more than half a standard deviation were considered "unchanging".

We then classified areas on the basis of change in the denominator, number of households, to capture overall demographic trends, particularly net migration patterns across areas. Similarly to UMBR, we used a standardised distribution of change in households and took half a standard deviation in either direction to identify change. Where the benefits data indicated the area was "improving", we distinguish places with net demographic increase. Where the benefits data indicated a rise in poverty we distinguished those places where the population (of households) was also falling.

Table 1 UMBR change across small areas in Great Britain, 2001-2006

\begin{tabular}{lllr}
\hline & Average (Percentage points) & Min & Max \\
\hline $\mathrm{UMBR}_{2006}-\mathrm{UMBR}_{2001}$ & 0.3 & -49.5 & 25.5 \\
\hline
\end{tabular}

Source: Authors' calculations on the basis of the dataset Unadjusted Means-tested Benefits Rate (UMBR) $\mathrm{UMBR}_{2001}$ is a 2 year moving average and $\mathrm{UMBR}_{2006}$ is a 3 year moving average of the original yearly UMBR 


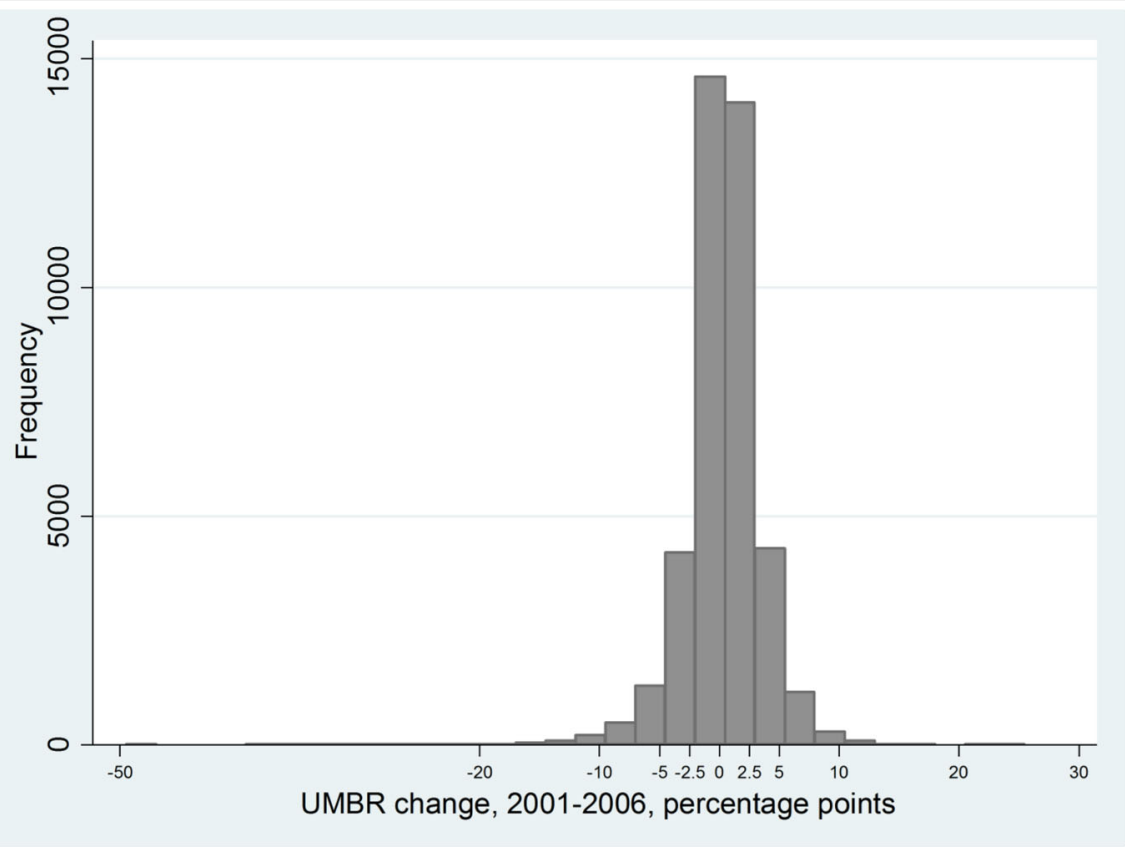

Fig. 1 Distribution of change in UMBR (UMBR2006-UMBR2001) in Great Britain. Source: Authors' calculations on the basis of the dataset Unadjusted Means-tested Benefits Rate (UMBR). Notes: $\mathrm{UMBR}_{2001}$ is a 2 year moving average; for all other years it is a 3 year moving average

Combining these two three-fold variables of change produced a six-fold classification of areas. ${ }^{4}$ Figure 2, taking Great Britain as a whole, shows the largest group at $44 \%$ with stable rates of benefit receipts and stable or rising population. They had distinctly low levels of means-tested benefit receipt — on average $14 \%$. Eight per cent of areas had a constant, relatively high level of deprivation, with signs of demographic decline. About one quarter each of the areas showed improvement (non-negligible reduction) or worsening (increase) on UMBR ( 23 and $25 \%$ respectively). The magnitude of change was greater where the demographic change was moving in a sympathetic directionUMBR falling and population of households going up (Area type 6), UMBR rising and population of households going down (Area type 1). These "extreme" types of areas (1 and 6) together accounted for about $17 \%$ of all areas. Area type 1 (UMBR rising and population falling) had the highest average rate of benefit claiming, at start and finish. Overall, the groups of places with changing UMBR, in either direction, were relatively disadvantaged.

The pattern varied across regions. Within England, the majority of LSOAs in East England, East Midlands, the South East and the South West belonged to the category 4,

\footnotetext{
${ }^{4}$ We collapsed the 9-fold variable created by cross classifying the two three-fold variables because some categories were too sparse. The six final categories reflected the combinations of demographic and benefit rate changes which were of most interest.
} 
Table 2 Incidence of UMBR change in Great Britain, 2001-2006

\begin{tabular}{|c|c|c|c|}
\hline $\begin{array}{l}\text { Change in UMBR between } 2001 \\
\text { and } 2006\left(\mathrm{UMBR}_{2006}-\mathrm{UMBR}_{2001}\right) \\
\text { in percentage points }\end{array}$ & Frequency & Percent & $\begin{array}{l}\text { Average level of UMBR } \\
\text { in } 2001 \text { (per cent) }\end{array}$ \\
\hline
\end{tabular}

\begin{tabular}{lrrr}
\hline UMBR change $\geq 5$ percentage pts & 3802 & 9.3 & 36.5 \\
$2.5 \leq$ UMBR change $<5$ & 8896 & 21.8 & 25.5 \\
$1 \leq$ UMBR change $<2.5$ & 13,711 & 33.5 & 18.4 \\
$0 \leq$ UMBR change $<1$ & 14,470 & 35.4 & 15.3 \\
\hline
\end{tabular}

Source: Authors' calculations on the basis of the dataset Unadjusted Means-tested Benefits Rate (UMBR) $\mathrm{UMBR}_{2001}$ is a 2 year moving average and $\mathrm{UMBR}_{2006}$ is a 3 year moving average of the original yearly UMBR

with low levels of UMBR in both 2001 and 2006 and population not falling, as did Wales. Regions in the north of England (North East, North West and Yorkshire and the Humber) had more change, with improvement dominating deterioration. London and West Midlands displayed intermediate incidence of change with deterioration outweighing improvement. The larger proportion of changes in Scotland is probably due to Datazones being smaller than LSOAs. That said, improvement clearly outweighed decline.

Figure 3 plots the changes in UMBR and population of households by the area classification produced by the Office of National Statistics (Bond and Insalaco 2007; ONS 2008), where the contrasts are greater than by region. Change was concentrated in particular types of areas. There was least change in Urban Fringe areas or Countryside. The average levels of UMBR were well below $20 \%$ at both time points in these types of area. White Collar Urban areas were similar, albeit with slightly less stability, and slightly higher UMBR. Instead, "all the action" seemed to occur in Multicultural City Life and Disadvantaged Urban communities, which had much smaller proportions with unchanging UMBR and higher levels of UMBR. Deterioration was much more prevalent in the Disadvantaged Urban Communities which had the highest proportion with rising (and high) benefit rates combined with falling population (Area type 1).

Table 3 Classification of changes: LSOAs and Datazones

\begin{tabular}{llcrl}
\hline $\begin{array}{l}\text { Area type } \\
\text { code }\end{array}$ & Area type label & Frequency & Percent & $\begin{array}{l}\text { Average level of UMBR } \\
\text { in 2001 (per cent) }\end{array}$ \\
\hline 1 & UMBR rising, population falling & 4503 & 11.02 & 29.1 \\
2 & UMBR rising, population NOT falling & 5796 & 14.18 & 19.8 \\
3 & UMBR steady, population falling & 3432 & 8.40 & 23.8 \\
4 & UMBR steady, population NOT falling & 17,856 & 43.68 & 14.2 \\
5 & UMBR falling, population NOT rising & 6731 & 16.47 & 28.2 \\
6 & UMBR falling, population rising & 2561 & 6.26 & 26.3 \\
\hline
\end{tabular}

Source: Authors' calculations on the basis of the dataset Unadjusted Means-tested Benefits Rate (UMBR) UMBR and population are defined as rising (falling) if their increase (decrease) between 2001 and 2006 was greater than 0.5 standard deviations. Population refers to household count 


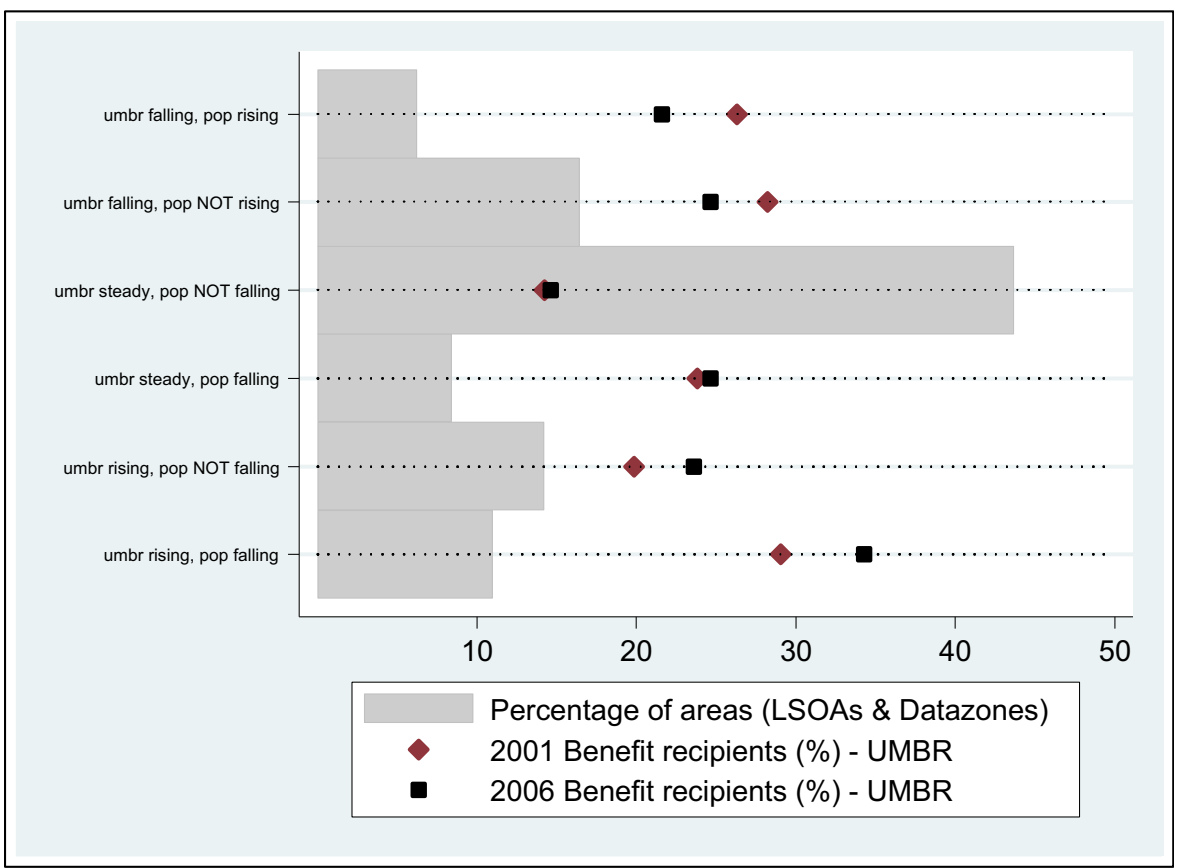

Fig. 2 UMBR and Population change. Source: Authors' calculations on the basis of the dataset Unadjusted Means-tested Benefits Rate (UMBR). Notes: UMBR and population are defined as rising (falling) if their increase (decrease) between 2001 and 2006 was greater than 0.5 standard deviations. Population refers to household count

Thus, UMBR can describe patterns of neighbourhood change which are not illuminated by other measures. The overall impression is of tranquillity in the more prosperous types of areas and more change, if not turbulence, in more disadvantaged places. It is particularly in inner cities where localities witnessed both improvements and declines.

\section{UMBR and Residential Mobility: Results from MCS}

So far we have shown that, when used cross-sectionally, UMBR is in line with other widely used measured of area deprivation, but unlike the IMDs it can help describe patterns of neighbourhood change. This section addresses two further questions. First, how well does UMBR reflect residents' perceptions of their neighbourhoods? This relates to the concern that objective measures may not correspond to subjective perceptions of neighbourhood characteristics. The second question relates to residential mobility. More specifically, can change as described by UMBR enrich our understanding of location choices? We answer both questions by matching UMBR data to the individual responses to the MCS.

The MCS is a nationally representative sample of births covering around 19,000 children born in the UK between September 2000 and January 2002. Families were interviewed for the first time when the children were aged 9 months (MCS1), mainly in 

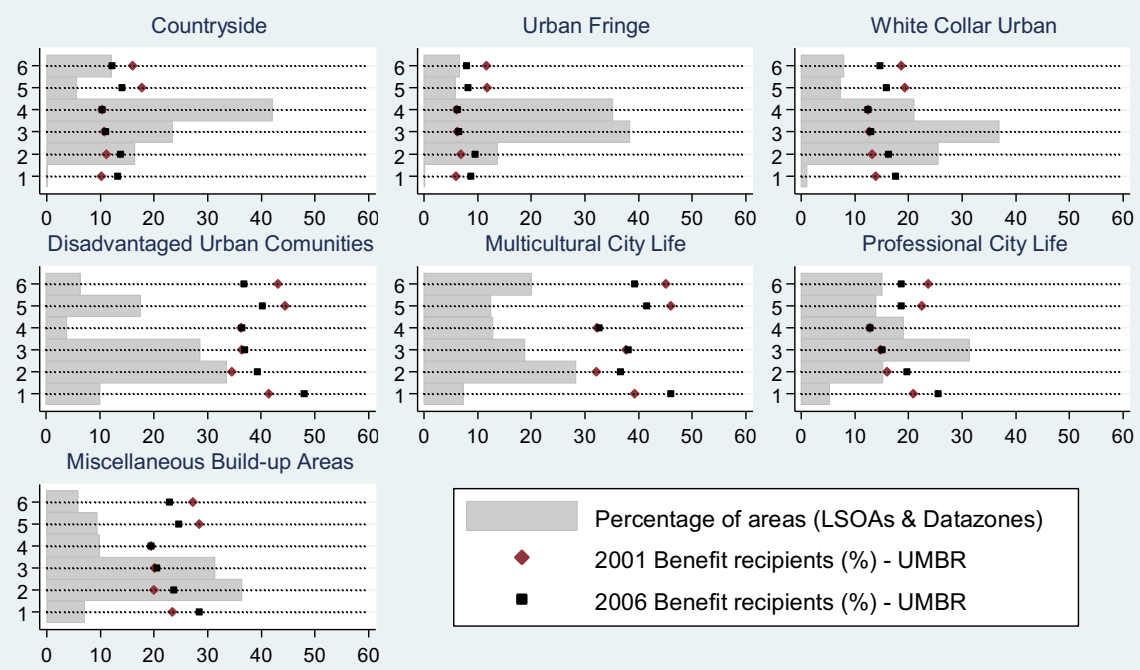

Fig. 3 UMBR and population change by ONS classification of places. Source: Authors' calculations on the basis of the dataset Unadjusted Means-tested Benefits Rate (UMBR). Notes: Area type code (vertical axis): 1 "UMBR rising, population falling"; 2 "UMBR rising, population NOT falling"; 3 "UMBR steady, population NOT rising"; 4 "UMBR steady, population rising"; 5 "UMBR falling, population NOT rising"; 6 "UMBR falling, population rising". UMBR and population are defined as rising (falling) if their increase (decrease) between 2001 and 2006 was greater than 0.5 standard deviations. Population refers to household count

2001. They were followed up when children were 3 years old, with interviews mainly in 2004 (MCS2), and when the children were aged 5, in 2006 (MCS3). Since then, MCS children and their families have been interviewed more, in 2008, 2012 and 2015. In this paper we concentrate on early childhood, before compulsory schooling, so use data from just the first three surveys.

An important feature of MCS is its clustered sample design (Plewis 2007). It oversamples children living in areas with high rates of child poverty or high minority ethnic populations. Thus MCS offers the opportunity to look closely at families living in poor areas. Furthermore, the MCS sample also over-samples in Scotland, Wales and Northern Ireland. As UMBR is unfortunately available only for Great Britain, we excluded the Northern Ireland sample from the MCS data.

Also by design MCS targets a specific demographic group - families with small children. The characteristics of the immediate surroundings are likely to be very relevant to children, whose regular interactions with people and institutions, such as day centres or playgrounds, tend to occur within a limited distance from their home. And indeed, parents of young children who have the possibility to do so tend to be particularly careful to select areas offering good conditions and resources for bringing up a family (Shonkoff and Phillips 2000). In addition, families with young children have often only recently moved to an area, and therefore have made their residential choice fairly recently. Indeed, among all families interviewed in Great Britain at MCS1, only $32 \%$ had lived at their address for more than 4 years. By the time the cohort child was five, more families had settled, with around $60 \%$ staying put between first and third surveys. Thus, MCS is an ideal dataset to study residential mobility. Moreover, 
comparing the subjective opinions of neighbourhood in the MCS with the UMBR score of the statistical area provides a particularly strong test of whether an objective poverty measure can reflect the "neighbourhood quality" perceived by residents.

We use the LSOA/DZ of residence at interview to match MCS interviews to UMBR data. Our analytical sample is confined to those families observed in Great Britain at all three sweeps. ${ }^{5}$ To define movers and stayers, we used two sources of informationself-reported moves and the geocodes attached to the place of residence. We defined as movers all those who explicitly reported a move, dropping from our analytical sample 786 observations who appeared to have changed LSOA/DZ between sweeps but did not report a move. This is because information on the reasons for moving could only be asked if moving was reported and because we did not want to treat as 'stayers' those whose moving status was not clear. After also discarding observations with incomplete information on their views about the neighbourhood we were left with 10,240 observations. Throughout the analysis we used weights that take into account the sample design and attrition up to MCS3 (Plewis 2007).

MCS allows respondents both to define subjective neighbourhood boundaries and to record their subjective views of the neighbourhood. At all three surveys, MCS recorded mothers' (or main respondents') views of the area they lived in. It was indicated that areas would be "within 20 min walk" from the respondents' home. Such a definition of area obviously varies by person to person depending on their mobility. It also allows a degree of flexibility for respondents to refer to their immediate surrounding or larger neighbourhood (Kearns and Parkes 2003). Such a definition does not necessarily coincide with the LSOA/DZ or other administrative boundaries. In densely populated areas, a 20 min walk will cover more than one LSOA/DZ. Hereafter we use the term "locality" or "neighbourhood" to indicate the area subjectively defined by respondents, while we continue to use the term "area" to refer to LSOAs and DZs. The difference in terminology, although rather arbitrary, serves as a reminder that when comparing UMBR with residents' views of their locality we cannot be sure that geography covered by the two definitions is the same.

The survey questions differed across sweeps. In MCS1 and MCS2 mothers were asked about their general satisfaction with their locality using a five point scale, from "very satisfied" to "very dissatisfied". At MCS2 and MCS3 respondents were asked whether the locality was good "to bring up children". With no question about general neighbourhood satisfaction in MCS3, there is no consistent information across all three sweeps.

Table 4 reports the average level of UMBR of the areas where MCS families lived in 2001, 2004 and 2006. UMBR levels in MCS are in line with the overall average for Great Britain, which, in 2001, was $21 \%$. Among areas falling in the top three deciles of UMBR, its average level was $40 \%$, with, in 2001, a minimum of $25 \%$ and a maximum of $88 \%$. Also in line with the evidence reported in the previous section, there was no visible variation in the average level of UMBR over time. Table 5 reports the distribution of MCS families across areas falling in the top $30 \%$ of UMBR distribution in Great Britain. At MCS1, $30 \%$ of families were in living in such high poverty areas.

\footnotetext{
${ }^{5}$ We have conducted separate analysis, available on request, on the larger sample of families who responded at MCS3. The pattern of results does not change, indicating that the movers included in our analytical sample are not biased towards a specific subgroup of movers.
} 
Table 4 UMBR levels in the areas where MCS families live

\begin{tabular}{llllr}
\hline & Mean $(\%)$ & Std. err. & {$[95 \%$ CI $]$} \\
\hline UMBR in 2001 (MCS1) & 20.9 & 0.006 & 19.7 & 22.2 \\
UMBR in 2004 (MCS2) & 20.7 & 0.006 & 19.5 & 21.8 \\
UMBR in 2006 (MCS3) & 20.4 & 0.005 & 19.3 & 21.5 \\
Unweighted number of observations & 10,240 & & &
\end{tabular}

Source: Authors' calculations on the basis of the dataset Unadjusted Means-tested Benefits Rate (UMBR) and MCS1-MCS3 data

Figures are weighted using MCS3 overall weights

That percentage had hardly changed by MCS3. Because MCS data allow looking at family-level poverty as well, we examined to what extent poor families were concentrated in high poverty areas. ${ }^{6}$ At MCS1, $60 \%$ of the families who were below the poverty line were living in the $30 \%$ poorest areas. And, similarly, $55 \%$ of the MCS families living in the $30 \%$ poorest areas were themselves below the poverty line. These data provide a useful reminder of the fact that area poverty and individual poverty are not synonymous. Not everyone who lives in a high poverty area is poor, and not all people who are poor live in high poverty areas (Townsend 1979).

Table 6 presents subjective opinions on neighbourhood. At both sweep 1 and sweep 2 , the great majority of respondents reported being either very or fairly satisfied with their locality. However, views on whether the neighbourhood was good for bringing up children were less positive, with 71 and $73 \%$ of respondents considering it good or very good. Families who did not move ("stayers") constituted around $60 \%$ of our sample. For them, any neighbourhood change happened "around" them. Among those who moved, $35 \%$ mentioned wanting a "better area" among the reasons for moving. This incudes those who explicitly said "better area", and also those who reported moving for "children's education", "school catchment area", or because they had "problems with neighbours" or because they wanted to "move away from crime". Other reasons reported in the survey comprised both positive reasons, such as wanting to be closer to families, as well as negative reasons, such as relationship breakdown or money problems (Ketende and McDonald 2008).

Were those expressing more positive opinions about their neighbourhood concentrated in areas with lower poverty rates? We start by looking at "stayers". Figures 4 and 5 (and similar plots, not shown, for the two measures of satisfaction from MCS2) suggest that those with the most positive views were more likely to be in areas with low poverty. At high levels of poverty negative views outweighed positive and neutral responses. We compared residents of the poorest $30 \%$ areas with those who living in the other $70 \%$. In the poorer areas, only $10 \%$ of residents said that their neighbourhood was excellent for bringing up children, in contrast with $41 \%$ of residents in the less poor areas. Seventeen

\footnotetext{
"We use the "headline" relative child poverty measure, which classifies as poor those families whose equivalised income is below $60 \%$ of the contemporary median UK income before housing costs (HMT 2007).
} 
Table 5 UMBR and family poverty

\begin{tabular}{|c|c|c|c|c|}
\hline \multirow{3}{*}{$\begin{array}{l}\text { Families in the } 30 \% \text { poorest (UMBR) area in } 2001 \text { (MCS1) } \\
\text { of whom, were themselves poor }\end{array}$} & \multirow{2}{*}{$\frac{\text { Mean }(\%)}{30.1}$} & \multirow{2}{*}{$\begin{array}{l}\text { Std. err. } \\
0.014\end{array}$} & \multicolumn{2}{|c|}{$[95 \% \mathrm{CI}]$} \\
\hline & & & 27.3 & 32.9 \\
\hline & 54.9 & 0.015 & 52.0 & 57.9 \\
\hline $\begin{array}{l}\text { Families below the poverty line in the } 30 \% \text { poorest (UMBR) } \\
\text { area in } 2001\end{array}$ & 60.4 & 0.022 & 56.0 & 64.8 \\
\hline Families in the $30 \%$ poorest (UMBR) area in 2006 (MCS3) & 28.4 & 0.013 & 25.9 & 30.9 \\
\hline of whom, were themselves poor & 54.7 & 0.016 & 51.6 & 57.9 \\
\hline $\begin{array}{l}\text { Families below the poverty line in the } 30 \% \text { poorest (UMBR) } \\
\text { area in } 2006\end{array}$ & 57.0 & 0.022 & 52.7 & 61.3 \\
\hline Unweighted number of observations & 10,240 & & & \\
\hline
\end{tabular}

Source: Authors' calculations on the basis of the dataset Unadjusted Means-tested Benefits Rate (UMBR) and MCS1-MCS3 data

Families below the poverty line are defined as those families whose equivalised income is below $60 \%$ of the contemporary median UK income (HMT 2007). Figures are weighted using MCS3 overall weights

per cent of mothers in areas with high levels of UMBR considered their locality as very poor for bringing up children, but less than $2 \%$ in the less poor areas took this view.

Movers provided further evidence on whether UMBR correlated with subjective opinions on neighbourhood. First of all, we find that families living in areas with higher UMBR were more likely to move (Table 7), and that the majority of them moved to areas that were less poor (Table 8). This is in line with the mobility literature, which suggests poverty is a "push factor", as people tend to move out of deprived areas and to improve their situation by moving (Rabe and Taylor 2010). By using UMBR, we are also able to quantify the magnitude of the changes. In case of moves to less poor areas, the area of destination was on average 12 percentage points less poor. In case of moves to poorer areas, 11 points poorer.

We then looked at those who said-retrospectively-that they had moved for reasons related to the new locality, implicitly suggesting that their current neighbourhood was better than the previous one. We expected this group would have gone to areas with lower UMBR than the original area. Table 9 (first row) confirms this: at the time of the first interview in 2001 these families had been living in areas with an average UMBR level of $22.5 \%$, while by 2006 , they had moved to areas with an average UMBR of $16.8 \%$. By contrast, movers who did not say they moved for a better neighbourhood, went to areas with, on average, a similar level of UMBR (Table 9 second row). That residents' opinions were in line with UMBR levels suggests that UMBR captures aspects of an area relevant to residents; this pattern emerges among stayers and movers alike.

The second part of the analysis explores what extent the dynamic description of areas afforded by UMBR can enrich our understanding of residential mobility. We start by looking at the type of area stayers and movers are found at in 2006, where we classify areas on the basis of their change in UMBR since 2001. Are movers flocking to areas that have been improving? We do not find any evidence of that. Instead, there is no significant difference in the distribution movers and stayers across areas with 
Table 6 Subjective opinions on neighbourhood and residential mobility

\begin{tabular}{|c|c|c|c|c|}
\hline & Mean $(\%)$ & Std. err. & \multicolumn{2}{|c|}{$[95 \% \mathrm{CI}]$} \\
\hline \multicolumn{5}{|l|}{ Satisfaction with locality in 2001 (MCS1) } \\
\hline Very satisfied & 44.5 & 0.011 & 42.3 & 46.6 \\
\hline Fairly satisfied & 39.1 & 0.008 & 37.5 & 40.7 \\
\hline Neither satisfied nor dissatisfied & 7.0 & 0.003 & 6.4 & 7.6 \\
\hline Fairly dissatisfied & 6.1 & 0.003 & 5.4 & 6.7 \\
\hline Very dissatisfied & 3.4 & 0.003 & 2.8 & 3.9 \\
\hline \multicolumn{5}{|l|}{ Satisfaction with locality in 2004 (MCS2) } \\
\hline Very satisfied & 49.5 & 0.011 & 47.4 & 51.6 \\
\hline Fairly satisfied & 37.0 & 0.008 & 35.4 & 38.7 \\
\hline Neither satisfied nor dissatisfied & 4.9 & 0.003 & 4.4 & 5.5 \\
\hline Fairly dissatisfied & 5.2 & 0.003 & 4.6 & 5.8 \\
\hline Very dissatisfied & 3.3 & 0.003 & 2.9 & 3.8 \\
\hline \multicolumn{5}{|c|}{ Whether locality is good for bringing up children in 2004 (MCS2) } \\
\hline Excellent & 32.4 & 0.011 & 30.2 & 34.7 \\
\hline Good & 40.2 & 0.009 & 38.5 & 41.9 \\
\hline Average & 19.4 & 0.006 & 18.2 & 20.6 \\
\hline Poor & 4.9 & 0.003 & 4.3 & 5.5 \\
\hline Very poor & 3.0 & 0.002 & 2.5 & 3.5 \\
\hline \multicolumn{5}{|c|}{ Whether locality is good for bringing up children in 2006 (MCS3) } \\
\hline Excellent & 31.9 & 0.011 & 29.9 & 34.0 \\
\hline Good & 41.6 & 0.008 & 40.0 & 43.1 \\
\hline Average & 20.2 & 0.007 & 18.9 & 21.6 \\
\hline Poor & 4.3 & 0.003 & 3.8 & 4.9 \\
\hline Very poor & 1.9 & 0.002 & 1.6 & 2.3 \\
\hline \multicolumn{5}{|l|}{ Residential mobility } \\
\hline Stayers & 59.6 & 0.008 & 58.0 & 61.3 \\
\hline Movers & 40.4 & 0.008 & 38.7 & 42.0 \\
\hline \multicolumn{5}{|l|}{ Of whom } \\
\hline Mentioned "better area" as reason for moving & 35.0 & 0.011 & 32.9 & 37.1 \\
\hline Unweighted number of observations & 10,240 & & & \\
\hline
\end{tabular}

Source: Authors' calculations on the basis of the dataset Unadjusted Means-tested Benefits Rate (UMBR) and MCS1-MCS3 data

Figures are weighted using MCS3 overall weights

different trends in $\mathrm{UMBR}^{7}$ (Table 10). This suggests that movers do not select their area of destination on the basis of what is happening to that area. Instead, they appear to simply compare it to their area of origin.

We test the usefulness of UMBR further, by focusing on the group of movers who had reached a poorer area than their original one. This is a sizable group: $38 \%$, as

\footnotetext{
${ }^{7}$ This result is confirmed when running a multinomial logistic regression on type of area and using moving status as regressor. 


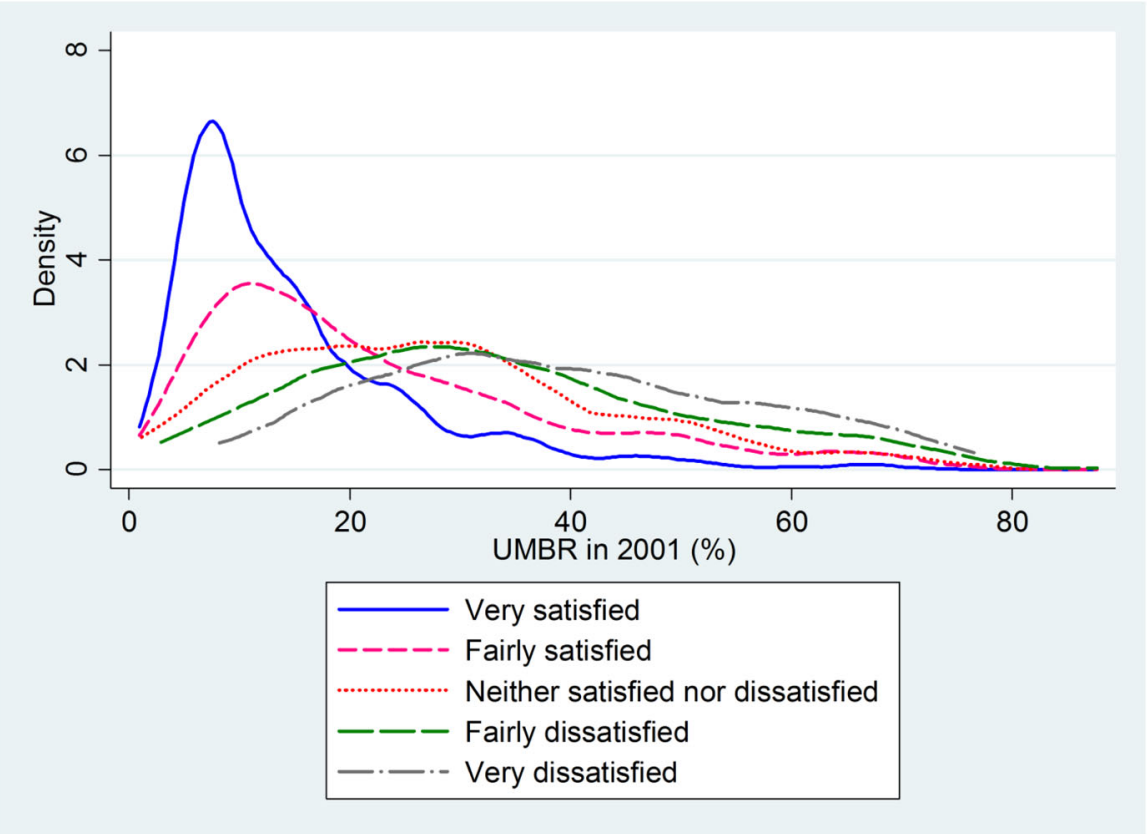

Fig. 4 UMBR in 2001 by neighbourhood satisfaction-MCS1. Source: Authors' calculations on the basis of the dataset Unadjusted Means-tested Benefits Rate (UMBR) and MCS1-MCS3 datasets. Notes: Sample: MCS1. Weighted using MCS3 overall weights

Table 8 indicates. Information on area changes can help us check whether these families were nevertheless better off in terms of area poverty by moving than by staying put. Perhaps they were escaping rapidly deteriorating areas? In fact that does not seem to be the case: $96.5 \%$ of the families who moved to poorer areas would have had less of an increase in UMBR if they had stayed at the original address (Table 11). Finally we examine whether these families were moving to improving areas. Perhaps they were choosing to live in a poorer area with the expectation that things were nonetheless improving. Again, that does not seem to be the case: only $19 \%$ of those moving to higher UMBR than at origin were found in areas with a falling UMBR (Table 12). Instead, $40 \%$ of these families appeared to be at double disadvantage: not only had they moved areas that were poorer than their area of origin but also to areas where poverty had been on the rise (Table 12).

\section{Summary and Conclusion}

This paper has presented a new indicator at small area level of poverty, to investigate whether its use could help overcome some of the challenges typically encountered in measuring neighbourhood change in residential mobility studies. The paper is the first to offer a full comparison between UMBR and the IMDs across Great Britain, the first to use it to analyse the extent of small area change in different types of areas, and the 


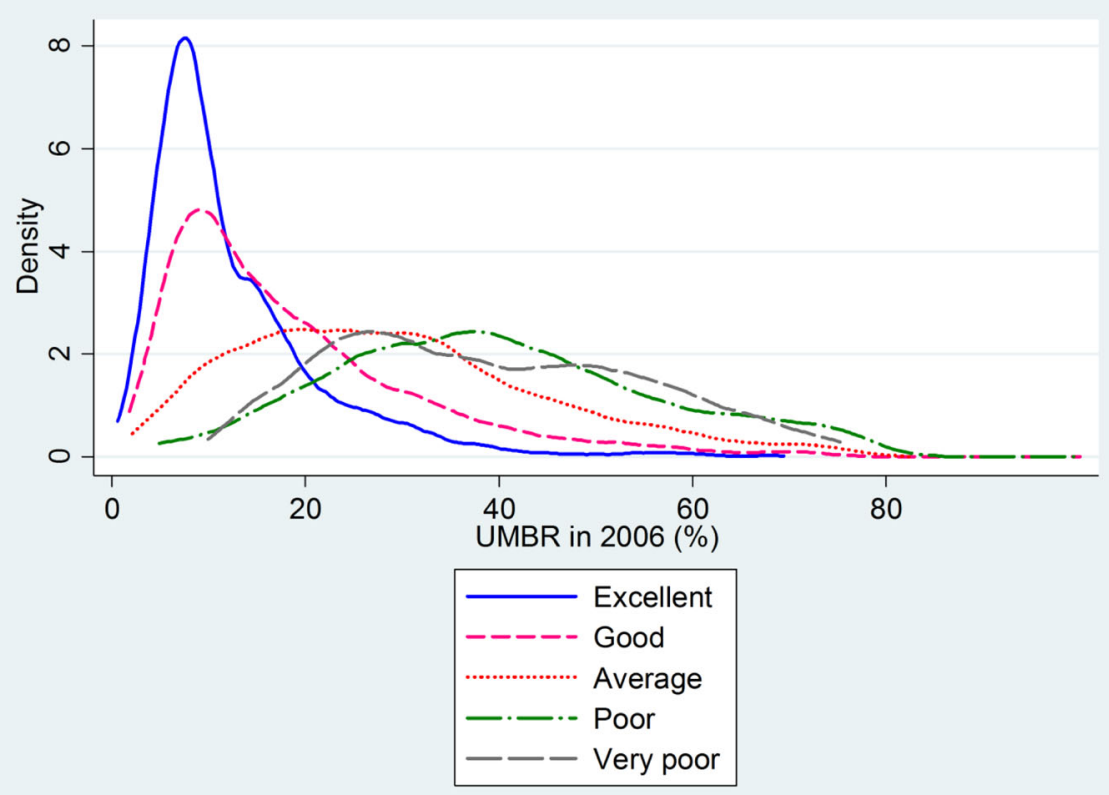

Fig. 5 UMBR in 2006 by whether neighbourhood is good for kids-MCS3. Source: Authors' calculations on the basis of the dataset Unadjusted Means-tested Benefits Rate (UMBR) and MCS1-MCS3 datasets. Notes: Sample: MCS3. Weighted using MCS3 overall weights

first to apply it to analysis of survey data. It provides a test case for the utility of UMBR as a measure of neighbourhood change over time or achieved by relocation.

UMBR suffers some of the same limitations as other publicly available measures of neighbourhood characteristics. It captures aggregate characteristics of residents rather than neighbourhood "quality" in terms of environment, amenities or community. Its definition of neighbourhood is a statistical one, not necessarily corresponding to subjective boundaries. Although it is conceptually and empirically narrower than

Table 7 Probability of moving, logistic regression

\begin{tabular}{lll}
\hline & Odds ratio & $t$ \\
\hline UMBR in 2001 & 2.60 & 5.01 \\
Constant & 0.55 & -9.62
\end{tabular}

$\mathrm{F}(1,328)=25.11$

Number of observations: 10,240

Authors' calculations on the basis of the dataset Unadjusted Means-tested Benefits Rate (UMBR) and MCS1MCS3 data

The dependent variable is 1 if the respondent has moved between MCS1 and MCS3. Results are weighted to take into account attrition and survey design 
Table 8 Comparing UMBR in areas of origin and areas of destination, by direction of change - movers subsample only

\begin{tabular}{llllll}
\hline & Proportion $(\%)$ & Std. err. & $\begin{array}{l}\text { Mean UMBR difference } \\
(\% \text { points })\end{array}$ & Freq. & Obs. \\
\hline Lower UMBR & 49.9 & 0.010 & 11.9 & 2,245 & 2,161 \\
Non change in UMBR & 12.4 & 0.007 & 0.3 & 585 & 437 \\
Higher UMBR & 37.7 & 0.011 & 11.3 & 1,680 & 1,381 \\
Total & 100 & & 1.7 & 4,510 & 3,979 \\
\hline
\end{tabular}

Authors' calculations on the basis of the dataset Unadjusted Means-tested Benefits Rate (UMBR) and MCS1MCS3 data

Figures are weighted using MCS3 overall weights, while the last column reports the number of unweighted observations

IMD, UMBR correlates very highly with indicators that capture other aspects of poverty.

UMBR's mathematical properties (a real number, with numerator and denominator available) make it suitable for analysis of change where IMDs are not. We looked at changes in UMBR between 2001 and 2006. This was a time of economic and employment growth, with a consistently low unemployment rate hovering at around $5 \%$ (ONS 2006: 58). The overall level of UMBR also remained stable. The overall distribution remained almost identical in all the years examined-2001-2006, a context of favourable economic conditions and stability. Within this context, our analysis uncovered some changes concentrated in specific types of area. Areas classified in 'disadvantaged urban communities' were more likely than areas elsewhere to witness an increase in UMBR, which appeared to be driven by an increase in number of benefit recipients combined with falling household population. By contrast, areas belonging to 'multicultural city centres' showed a more balanced, though diverse, trajectory, with increases in UMBR as common as stability and decreases.

Besides describing what UMBR tells us about small area change in Great Britain, we have explored its usefulness for the study of residential mobility, matching UMBR to MCS data. First, we have examined the correspondence between objective and subjective measures of local conditions. Broadly, we find that residents in areas with

Table 9 Average level of UMBR among movers, by reason for moving

\begin{tabular}{|c|c|c|c|c|c|c|c|c|}
\hline & \multicolumn{4}{|c|}{ Average UMBR in 2001 (MCS1) } & \multicolumn{4}{|c|}{ Average UMBR in 2006 (MCS3) } \\
\hline & \multirow{2}{*}{$\begin{array}{l}\text { Mean }(\%) \\
22.5\end{array}$} & \multirow{2}{*}{$\begin{array}{l}\text { Std. err. } \\
.008\end{array}$} & \multicolumn{2}{|c|}{$[95 \% \mathrm{CI}]$} & \multirow{2}{*}{$\begin{array}{l}\text { Mean (\%) } \\
16.8\end{array}$} & \multirow{2}{*}{$\begin{array}{l}\text { Std. err. } \\
.005\end{array}$} & \multicolumn{2}{|c|}{$[95 \% \mathrm{CI}]$} \\
\hline Moved for a better area & & & 21.0 & 24.0 & & & 15.7 & 17.8 \\
\hline Mover for all other reasons & 22.2 & .007 & 20.8 & 23.6 & 22.5 & .006 & 21.4 & 23.7 \\
\hline
\end{tabular}

Source: Authors' calculations on the basis of the dataset Unadjusted Means-tested Benefits Rate (UMBR) and MCS1-MCS3 data

Figures are weighted using MCS3 overall weights 
Table 10 Distribution of stayers and movers across type of areas at MCS3

\begin{tabular}{|c|c|c|c|c|}
\hline Over & Proportion $(\%)$ & Std. err. & \multicolumn{2}{|c|}{ [95\% Conf. interval] } \\
\hline \multicolumn{5}{|c|}{ 1. UMBR rising } \\
\hline Stayers & 0.25 & 0.017 & 0.21 & 0.28 \\
\hline Movers & 0.27 & 0.012 & 0.25 & 0.29 \\
\hline \multicolumn{5}{|c|}{ 2. UMBR steady } \\
\hline Stayers & 0.52 & 0.018 & 0.49 & 0.56 \\
\hline Movers & 0.53 & 0.011 & 0.51 & 0.55 \\
\hline \multicolumn{5}{|c|}{ 3. UMBR falling } \\
\hline Stayers & 0.23 & 0.017 & 0.20 & 0.27 \\
\hline Movers & 0.20 & 0.010 & 0.18 & 0.22 \\
\hline \multicolumn{5}{|c|}{ Number of observations: 10,240} \\
\hline
\end{tabular}

Authors' calculations on the basis of the dataset Unadjusted Means-tested Benefits Rate (UMBR) and MCS1MCS3 data

Figures are weighted using MCS3 overall weights

high level of UMBR tended to express lower satisfaction with their neighbourhood than those living in areas with lower UMBR. Poorer areas were also viewed as worse places for bringing up children. Families who moved because they wanted a better neighbourhood went to areas which were considerably less poor than the areas they left. Thus what constitutes a "better neighbourhood", subjectively, appeared to correlate to UMBR levels to an extent. This result allays fears that objective measures of neighbourhood characteristics available at predefined geographies may misrepresent the reality of neighbourhoods for some people who live there.

Second, we examined families' moves from one neighbourhood to another against poverty trends within neighbourhood themselves. In line with previous studies of residential mobility, our findings show that the absolute difference in poverty between area of origin and area of destination appears to be what matters to relocation choices. However, we are able to show that a large proportion of families who moved to poorer neighbourhoods were at double disadvantage: not only was the area poorer than the original one, but they often moved to declining areas.

Overall this paper has shown how, pragmatically, UMBR can satisfactorily capture several aspects of deprivation that may affect the residents of an area. It has also shown

Table 11 Percentage of movers to poorer areas whose area of origin became poorer than their area of destination

Mean $(\%)$ Std. err. $\quad[95 \%$ Conf. interval $]$

In area that is less poor than what area of origin has become $\quad \begin{array}{lllll}0.03 & 0.007 & 0.02 & 0.05\end{array}$

Number of observations: 1,381

Authors' calculations on the basis of the dataset Unadjusted Means-tested Benefits Rate (UMBR) and MCS1MCS3 data

Figures are weighted using MCS3 overall weights. 
Table 12 UMBR trends in areas of destination of movers whose area of origin had lower UMBR than their area of destination

\begin{tabular}{lcr}
\hline & Frequency & Percent \\
\hline 1. UMBR rising & 552 & 39.94 \\
2. UMBR steady & 568 & 41.12 \\
3. UMBR falling & 262 & 18.94 \\
Total & 1381 & 100 \\
\hline
\end{tabular}

Source: Authors' calculations on the basis of the dataset Unadjusted Means-tested Benefits Rate (UMBR) and MCS1-MCS3 data

Figures are weighted using MCS3 overall weights and are rounded

that it is broadly in line with the opinions and moving behaviour of families with young children surveyed in the MCS. This is important when dealing with existing data and has relevance for future survey design. We therefore conclude that UMBR is capable of enhancing the information on neighbourhood available in Millennium Cohort Study and potentially other longitudinal studies and that these micro data are capable or enriching the understanding of the administratively based national statistics.

Acknowledgments This paper is part of a larger project on Home Moves in the Early Years (ESRC grant ES/K000438/1). The support to accessing the dataset Millennium Cohort Study, 2001-2008, Geographical Identifiers, Lower Super Output Areas by the Secure Data Service at the UK Data Archive is gratefully acknowledged. The families taking part in the Millennium Cohort Study are thanked for their cooperation.

Open Access This article is distributed under the terms of the Creative Commons Attribution 4.0 International License (http://creativecommons.org/licenses/by/4.0/), which permits unrestricted use, distribution, and reproduction in any medium, provided you give appropriate credit to the original author(s) and the source, provide a link to the Creative Commons license, and indicate if changes were made.

\section{References}

Bond, S., \& Insalaco, F. (2007). 2001 Area classification of Super Output Areas and Datazones. Project final report. London: ONS.

Briggs, X. D. S., Popkin, S. J., \& Goering, J. M. (2010). Moving to opportunity: The story of an American experiment to fight ghetto poverty. New York: Oxford University Press.

Butler, T. (2007). Re-urbanizing London Docklands: gentrification, suburbanization or new urbanism? Reurbanizing London Docklands. International Journal of Urban and Regional Research, 31(4), 759-781.

Clapham, D. (2005). The meaning of housing: A pathways approach. Bristol: Policy Press.

Cohn, M. J., \& Jackman, S. P. (2011). A comparison of aspatial and spatial measures of segregation. Transactions in GIS, 15, 47-66.

Fenton, A. (2013a). Post-censal houshold estimates for small areas. Social policy in a cold climate research note series RN003. London: Centre for Analysis of Social Exclusion, LSE.

Fenton, A. (2013b). Small-area measures of income poverty. CASE Paper No 173. London: London School of Economics.

Foden, M., Fothergill, S., \& Gore, T. (2014). The state of the coalfields: Economic and social conditions in the former mining communities of England, Scotland and Wales. Sheffield: Centre for Regional Economic and Social Research.

Galster, G. C. (2012). The mechanism(s) of neighborhood effects theory, evidence, and policy implications. In M. van Ham, D. Manley, N. Bailey, L. Simpson, D. Maclennan (Eds.) Neighbourhood Effects Research: New Perspectives. Dordrecht: Springer. 23-56. 
HM Treasury. (2007). PSA delivery agreement 9: Halve the number of children in poverty by 2010-2011, on the way to eradicating child poverty by 2020. London: TSO.

Jellyman, T., \& Spencer, N. (2008). Residential mobility in childhood and health outcomes: a systematic review. Journal of Epidemiology and Community Health, 62, 584-592.

Kearns, A., \& Parkes, A. (2003). Living in and leaving poor neighbourhood conditions in England. Housing Studies, 18(6), 827-851.

Kearns, A., \& Parkinson, M. (2001). The significance of neighbourhood. Urban Studies, 38(12), 2103-2110.

Ketende, S. C., \& McDonald, J. W. (2008). Housing, neighbourhood and residential mobility. In K. Hansen \& H. Joshi (Eds.), Millennium cohort study: Third survey guide to initial findings. London: Centre for Longitudinal Studies.

Kwan, M.-P. (2012). The uncertain geographic context problem. Annals of the Association of American Geographers, 102(5), 958-968.

Lupton, R. (2003). Poverty street: The dynamics of neighbourhood decline and renewal. Bristol: Policy Press.

Lupton, R., \& Fitzgerald, A. (2015). The coalition's record on area regeneration and neighbourhood renewal. SPCC working paper 19. London: Centre for Analysis of Social Exclusion, LSE.

Massey, D. B. (1994). Space, place and gender. Cambridge: Polity Press.

McLennan, D., Barnes, H., Noble, M., Davies, J., Garratt, E., \& Dibben, C. (2011). The English indeces of deprivation 2010. London: Department for Communities and Local Government.

National Assembly for Wales (Statistical Directorate). (2005). Welsh index of multiple deprivation 2005. Technical report. Cardiff: National Assembly for Wales.

Norman, P. (2010). Identifying change over time in small area socio-economic deprivation. Applied Spatial Analysis and Policy, 3(2-3), 107-138.

Northern Ireland Statistics and Research Agency. (2005). Northern Ireland multiple deprivation measure. 2005. Belfast: Northern Ireland Statistics and Research Agency.

Office for National Statistics (ONS). (2006). Labour market review. Norwich: HMSO. Available at http://www.ons.gov.uk/ons/publications/re-reference-tables.html?edition=tcm\%3A77-47008.

Office of National Statistics (ONS). (2008). Guidance notes for the 2001 area classification of super output areas and data zones. London: ONS.

Office of the Deputy Prime Minister. (2004). The English indices of deprivation 2004 (Revised ed.). London: Office of the Deputy Prime Minister.

Orford, S., \& Leigh, C. (2014). The relationship between self-reported definitions of urban neighbourhood and respondent characteristics: a study of Cardiff, UK. Urban Studies, 51(9), 1891-1908.

Payne, R. A., \& Abel, G. A. (2012). UK indices of multiple deprivation - a way to make comparisons across constituent countries easier. Health Statistics Quarterly, (53), 22-37.

Plewis, I. (2007). The millennium cohort study: Technical report on sampling. London: Centre for Longitudinal Studies.

Power, A., \& Mumford, K. (1999). The slow death of great cities: Urban abandonment or urban renaissance? York: Joseph Rowntree Foundation.

Rabe, B., \& Taylor, M. (2010). Residential mobility, quality of neighbourhood and life course events. Journal of the Royal Statistical Society: Series A (Statistics in Society), 173(3), 531-555.

Robinson, D. (2010). The 'time-space' biographies of daily life in deprived neighbourhoods. Living through change in challenging neighbourhoods. Research paper no. 3. Sheffield: Centre for Regional Economic and Social Research, Sheffield Hallam University.

Scottish Executive (Office of the Chief Statistician). (2004). Scottish index of multiple deprivation 2004: Technical report. Edinburgh: Scottish Executive.

Shonkoff, J. P., \& Phillips, D. (2000). From neurons to neighborhoods: The science of early child development. Washington, D.C.: National Academy Press.

Townsend, P. (1979). Poverty in the United Kingdom: A survey of household resources and standards of living. Harmondsworth: Penguin.

Tunstall, R., \& Coulter, A. (2006). Progress on twenty 'unpopular' estates, 1980-2005. Joseph Rowntree Foundation: York.

Tunstall, H., Pickett, K., \& Johnsen, S. (2010). Residential mobility in the UK during pregnancy and infancy: are pregnant women, new mothers and infants "unhealthy migrants"? Social Science \& Medicine, 71(4), 786-798.

Vallée, J., Le Roux, G., Chaix, B., Kestens, Y., \& Chauvin, P. (2014). The 'constant size neighbourhood trap' in accessibility and health studies. Urban Studies.

Van Ham, M., Manley, D., Bailey, N., Simpson, L., \& Maclennan, D. (Eds.). (2012). Neighbourhood effects research, new perspectives. Dordrecht: Springer.

Verropoulou, G., Joshi, H., \& Wiggins, R. D. (2002). Migration, family structure and children's well being: a multilevel analysis of the second generation of the 1958 birth cohort study. Children and Society, 16, 219-231. 